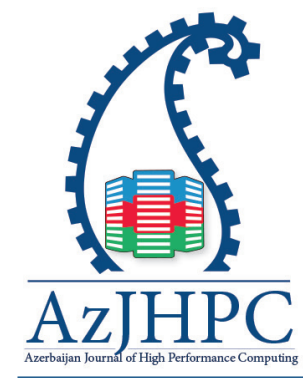

${ }^{*}$ Correspondence: Nguyen Ha Huy Cuong, Vietnam-Korea University of Information and Communication Technology Da Nang City, Vietnam, nhhcuong@vku.udn.vn

\title{
Information Technology Infrastructure for Smart Tourism In Da Nang City
}

Nguyen Ha Huy Cuong ${ }^{1}$, Nguyen Trong Tung ${ }^{2}$, Nguyen Van Hong Quang ${ }^{3}$, Nguyen Nhat Tan ${ }^{4}$, Ngo Quoc Huy ${ }^{5}$, Trinh Cong Duy ${ }^{6}$

\author{
${ }^{1}$ Vietnam-Korea University of Information and Communication Technology, Da Nang City, \\ Vietnam,nhhcuong@vku.udn.vn \\ 2Dong-A University, Da Nang City, Vietnam, tungntda@gmail.com \\ ${ }^{3}$ The University of Da Nang - University of Foreign Language Studies, Da Nang City, \\ Vietnam,nvhquang@ufl.udn.vn \\ ${ }^{4}$ Department of Science and Technology of Quangnam Province, Quang Nam, Vietnam, \\ tandost@gmail.com \\ ${ }^{5}$ HALOVI Information Technology JSC, Da Nang City, Vietnam, nqhuydn@gmail.com \\ ${ }^{6}$ The University of Da Nang - Software Development Centre, Da Nang City, Vietnam, \\ tcduy@sdc.udn.vn
}

\begin{abstract}
A smart tourism system has an important role in using information and communication technology to form an intelligent tourism ecosystem, build a high-quality tourism industry to serve tourists, contributing to sustainable economic development. An integrated database is an important platform that provides information for destinations in smart tourism development. In line with current tourism development needs, a database should be built in the direction of integrating the largest information possible. The information contained in it should cover many aspects of the visitors' requirements including location and spatial relations as well as object specification features. In order to have a truly smart tourism environment, certain investments in database development are really necessary for localities that want to develop this trend. The database is built for smart tourism based on GIS (Geographic Information Systems) is a new direction with the development of IT infrastructure, not outside of building smart cities.
\end{abstract}

Keyword: Smart tourism system; Infrastructure; GIS; Cloud Computing; Resource Allocation

\section{Introduction}

The outstanding development of science and technology in recent years, intelligent technologies have gradually been applied in many areas of human life. Along with that development trend, the orientation for the destinations in the current development strategy is smart tourism. Indeed, tourists today are increasingly familiar with the use of modern technology to support their travels. Therefore, tourism organizers must also develop technology infrastructure in a way that meets the wishes of tourists using the technology. Simultaneously, developing a smart tourism environment is also a means to promote efficiency and increase attractiveness according to current trends. 
In order for the locality to build a smart tourism environment, there are many demands placed on both hardware and software. The technical infrastructure is one of the fundamental issues to be completed first. In which, information source plays an extremely important and decisive role in the operation of the whole system. A smart destination management system always needs data to perform functions, meeting the needs of multiple users. Therefore, establishing a well-integrated database will be a solid foundation for developing smart local tourism capabilities.

The authors analyze the requirements that a local tourism smart database must meet on a theoretical basis, combined with assessments of the practical requirements of tourism activities. From there, propose a sample database model for local can be built to meet the information needs of all tourists.

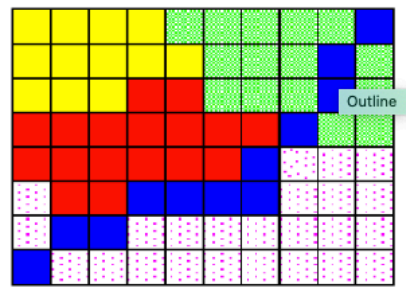

- Stores images as rows and
columns of numbers with a
Digital Value/Number (DN) for
each cell
- Units are usually represented
as square grid cells that are
uniform in size.
- Cells often called pixels
(picture elements); raster data
often called image data

Fig. 1. Raster map

\section{Smart tourism concept}

"Smart" has become a new popular word to describe the technological, economic, and social development driven by technology based on sensor types, big data, open data, binding protocols. Connection and exchange of new information (e.g., Internet of Things, RFID, and NFC) as well as the ability to reason and think (Gretzel, Reino, Kopera, \& Koo, 2015). In tourism, intelligence is used to talk about a complex synthesis of everything from smart cities to connectivity to infrastructure (Gretzel, Sigala, Xiang, \& Koo, 2015). From this basis, Gretzel et al. (2015) proposed the definition of smart tourism as "tourism is supported by integration efforts at one destination to collect and synthesize/exploit data obtained from physical infrastructure, social links, government / organizational resources, and the human body/mind associated with the use of advanced technology to transform data into the on-site experience and propose business value with a clear focus on efficiency, sustainability, and enriching experience."

Smart tourism is an inevitable development step from traditional tourism and later e-tourism. Smart tourism is formed with the background of innovation and technology orientation of industry and consumers. Besides, the widespread application of 
information and communication technology (ICT) in tourism also contributed to this formation. For example, the global distribution form and central booking system integrate web-based technologies (Buhalis, 2003; Werthner \& Ricci, 2004). Gretzel et al. (2015) suggest that smart tourism is included. Many smart components and layers are supported by ICT. Smart tourism components include smart destinations, smart experiences, and smart business ecosystems; they also collect, exchange, and process data identified as layers of smart travel. These components and classes are illustrated in Figure 2.

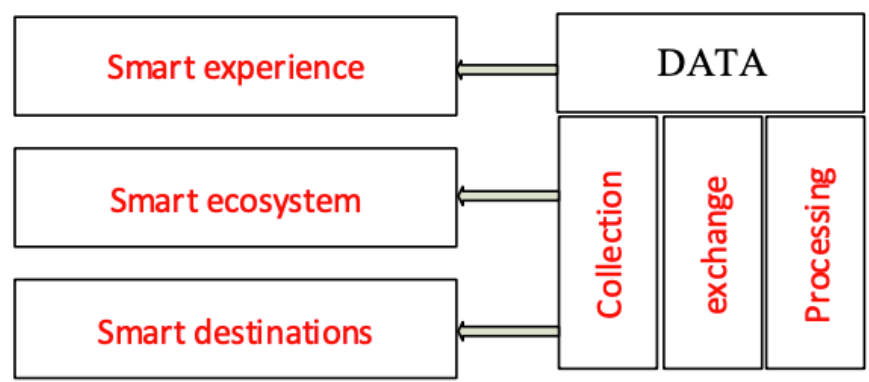

Fig. 2. Component and class of smart tourism

Today, there is still no clear distinction between smart tourism and e-tourism because ICT, information systems and social media concepts in smart tourism are also important for e-tourism (Gretzel, Sigala, et al., 2015; Li, Hu, Huang, \& Duan, 2017; CW Yoo, Goo, Huang, Nam, \& Woo, 2017). The differences between smart tourism and e-tourism are summarized in Table 1.

Table 1: Differences between smart tourism and e-tourism (Gretzel, Sigala, et al., 2015)

\begin{tabular}{|c|c|c|}
\hline & E-tourism & Smart tourism \\
\hline Area & Digital & Digital \& physical bridge \\
\hline Core technology & Websites & Sensors and smartphones \\
\hline Travel period & Before \& after the tour & During the tour \\
\hline Core throughout & Information & Big data \\
\hline Paradigm & Interactive & $\begin{array}{c}\text { Co-creation through inter- } \\
\text { mediaries } \\
\text { technology }\end{array}$ \\
\hline Structure & Value chain / intermediary & Ecosystem \\
\hline Exchange & $\begin{array}{c}\text { Business to Business, } \\
\text { Business with Customers, } \\
\text { Customers with Customers }\end{array}$ & Public-private partnership \\
\hline
\end{tabular}

The definition of smart tourism presented above also received an inadequate assessment because of too much emphasis on ICT but a lack of environmental 
factors (Yalçınkaya, Atay, \& Korkmaz, 2018). Yalçınkaya et al. (2018) suggested that environmental awareness should be included in the definition of smart tourism, citysmart destinations, and destinations as defined by the World Tourism Organization.

\section{Background of smart tourism}

"Buhalis and Amaranggana (2013) identify three main components of the ICT necessary to enhance smartness in a tourism destination: "Cloud Computing, Internet of Things (IoT) and End-User Internet Service System." Cloud Computing helps to reduce fixed costs and to share information. IoT means that not just screens are connected via the Internet, but also other items and that they all illustrate one big network. The IoT generally supports "providing information and analysis as well as automation and control," while the End-User Internet Service System refers to different applications at different levels (Buhalis \& Amaranggana, 2013). An important content of a smart destination is the integration of ICT into the infrastructure to enhance competition and improve the quality of life of all stakeholders, including local residents and guests. (Boes, Buhalis, \& Inversini, 2015; Buhalis \& Amaranggana, 2013; Caragliu, Del Bo, \& Nijkamp, 2011; Gretzel, Zhong, \& Koo, 2016). In addition to destination composition, smart tourism is a social phenomenon arising from a combination of ICT with travel experience (Hunter, Chung, Gretzel, \& Koo, 2015). Smart experiences are especially focused on technology-driven travel, personalization, contextual awareness, and realtime monitoring (Buhalis \& Amaranggana, 2013; Neuhofer, Buhalis, \& Ladkin, 2015). The third component, the smart business ecosystem, addresses the complex business ecosystem that contributes to and facilitates the exchange of tourism resources and co-creates travel experiences (Buhalis \& Amaranggana. 2013). Dynamic stakeholders characterize the business component of smart tourism, electronicizing the core business processes and organizational flexibility (Buhalis \& Amaranggana, 2013). Collaboration between the public and private sectors is the difference between the business intelligence component. This can lead to governments becoming more open and becoming suppliers of infrastructure and data.

In smart tourism, three layers are covering the three components above: an intelligent information layer geared towards data collection; an intelligent exchange layer that supports connectivity; and an intelligent processing layer responsible for analyzing, visualizing, integrating, and using data (Tu \& Liu, 2014). ICT is the key to the conceptualization and development of smart tourism. ICT will provide consumers and travel service providers with more relevant information in a smart tourism environment, support better decisions, greater mobility, and ultimately experience more interesting travel experiences (Gretzel, 2011; Sigala \& Chalkiti, 2014; Werthner, 2002).

From a visitor's perspective, these systems assist travelers by 1) estimating user needs based on a variety of factors and giving suggestions for favorite places to eat and drink. Moreover, entertainment; 2) increase the visitor experience at the site by providing additional information, recommending services tailored to personal 
preferences; 3) allow visitors to share their own experiences to assist other travelers in making decisions (Gretzel, Reino, et al., 2015; Gretzel, Sigala, et al., 2015). From a tourism industry perspective, these intelligent systems play a role in infrastructure and contribute to automating business processes, increasing efficiency, supporting new product design, forecasting, and managing risk management - crisis (Sigala 2011, 2012; Washburn et al., 2009; Werthner, 2002; K.-H. Yoo, Sigala, \& Gretzel, 2016).

\section{The integrated database meets smart tourism requirements}

Ensuring the source of information is a factor that must be a top priority when deploying a smart travel destination. All components of smart tourism in operation must be based on important information. Without information, system components would not be able to operate and perform their functions. Therefore, ensuring the source of information is a factor that must be given top priority when deploying a smart tourism destination.

Characteristics of information related to data and knowledge, data representing values assigned to parameters, and knowledge that indicate an understanding of facts or abstract concepts (Merriam- Webster, 2019). Therefore, to get rich and efficient information in mining, a really large and systematic amount of data is collected. This collection of data is stored and managed through a computer system in the form of a database. With the task of effectively managing the necessary information, the database plays an important role in smart travel destinations system structure.

The current demand for information in tourism, the integrated database of attribute information, and spatial information is the direction to choose which brings many advantages.

This database model allows user applications to access not only specific descriptive information about the object of interest but also helps to locate and assist in handling a lot of spatial questions - something that travelers Calendars are often interested in activities. The questions asked by travelers often ask about both attributes and space, such as: What? Where?

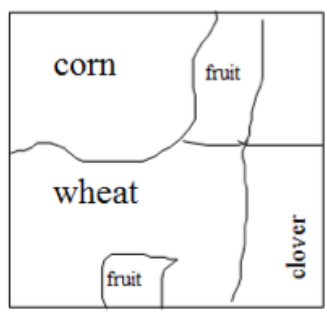

\begin{tabular}{|c|c|c|c|c|c|c|c|c|c|c|}
\hline & 0 & 1 & 2 & 3 & 4 & 5 & 6 & 7 & 8 & 9 \\
\hline 0 & 1 & 1 & 1 & 1 & 1 & 4 & 4 & 5 & 5 & 5 \\
\hline 1 & 1 & 1 & 1 & 1 & 1 & 4 & 4 & 5 & 5 & 5 \\
\hline 2 & 1 & 1 & 1 & 1 & 1 & 4 & 4 & 5 & 5 & 5 \\
\hline 3 & 1 & 1 & 1 & 1 & 1 & 4 & 4 & 5 & 5 & 5 \\
\hline 4 & 1 & 1 & 1 & 1 & 1 & 4 & 4 & 5 & 5 & 5 \\
\hline & 2 & 2 & 2 & 2 & 2 & 2 & 2 & 3 & 3 & 3 \\
\hline & 2 & 2 & 2 & 2 & 2 & 2 & 2 & 3 & 3 & 3 \\
\hline 7 & 2 & 2 & 2 & 2 & 2 & 2 & 2 & 3 & 3 & 3 \\
\hline & 2 & 2 & 4 & 4 & 2 & 2 & 2 & 3 & 3 & 3 \\
\hline & 2 & 2 & 4 & 4 & 2 & 2 & 2 & 3 & 3 & 3 \\
\hline
\end{tabular}

Fig. 2a. Raster map representation on the computer 
What are their characteristics? How far is it to there? Which is the best way to get there? .. These questions can be answered well with a management system that exploits spatial information integration databases. These databases are a type of geographic information system (GIS) application that has been widely developed worldwide.

Developing a database to meet smart tourism will gather all necessary information about local tourism, catering for many types of objects according to different needs. To serve a wide range, with different capacities and qualifications, the database needs to be designed in a simple but detailed and specific way to provide useful information and facilitate easy queries when needed. Besides, specific technical requirements must be met to suit local infrastructure. Within the scope of this study, we will only focus on the information organization structure to provide recommendations for effective information management for localities in tourism development.

In actual tourism activities, the demand for information is extremely diverse. With a smart tourism destination, the demand for information is much higher, covering many areas of visitor interest (Fodness \& Murray, 1997). To meet the needs of tourists, the database needs to be built with necessary information layers, including:

- Background data: provincial, district, and commune administrative; topographic; aquatic system; roads, overlays, typical socio-economic spots (post office, hospital, bank, administrative offices, ...)

- Specialized data: natural tourist sites, humanistic tourism, hotels, restaurants, entertainment areas, cafes - bars, health care services, travel services, transportation services, shopping, ...

These data layers will include spatial information and all attribute information about the objects of interest in local tourism activities. Depending on the selected data model, the data layers will have a way of organizing in a way that is reasonable and most effective in the application deployment and development process.

Data consistency must be maintained at a high level and open to facilitate the sharing of data exchanges with relevant industries and meet the need to upgrade and expand the scope of the space. Database once the development needs of society in the future.

Tourism is an area that requires constant innovation to meet tourists' needs and

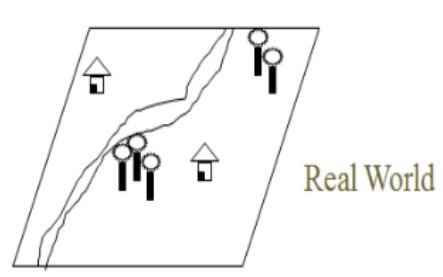

Vector Representation

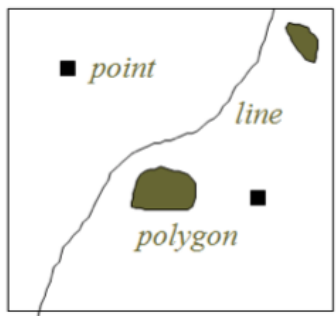

Fig. 2b. Vector map representation 
always creates an attraction to attract visitors. Besides, in the development of society, the structure and face of the society are constantly changing, and of course, all elements of the tourism industry are always changing. Therefore, tourism data are dynamic data that requires constant updates to be closely aligned with the actual development situation, and the database must meet the criteria for easy updating.

\section{Proposing the information structure of the integrated database}

The integrated database includes spatial data and attributes data about managed objects.

- Spatial data relate to the geometry of spatial features

- Attribute data describe the characteristics of the spatial feature

In particular, spatial data or map data are information describing the shape, size, and location of objects that exist in reality. Attribute data are data that describe the characteristics of specific objects. They are linked together to represent complete information about an object.

GIS (geo relational data model) stores spatial data and attribute data separately and links the two by the feature ID. The two data sets are synchronized to be queried, analyzed, and displayed in unison. The geo relational Data Model stores spatial and attribute data separately: spatial data ("geo") in graphic files and attribute data ("relational") in a relational database.

According to the way of organizing data according to the relational model along with the required characteristics of the tourist information field of a destination, the structure of attribute information in the database is organized into two groups: background data and data. thematic material

\subsection{Background data layers}

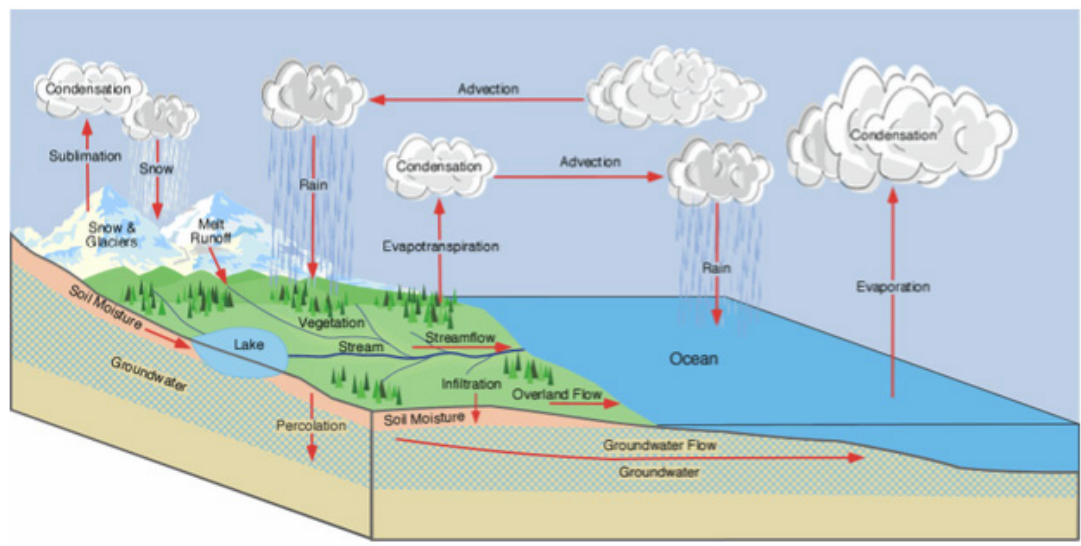

Fig. 3. Realistic model background map 
Information layers for local spatial areas provide general geographic features, including administrative boundaries, topography, hydrology, roads, socio-economic points, etc. Fig 4.

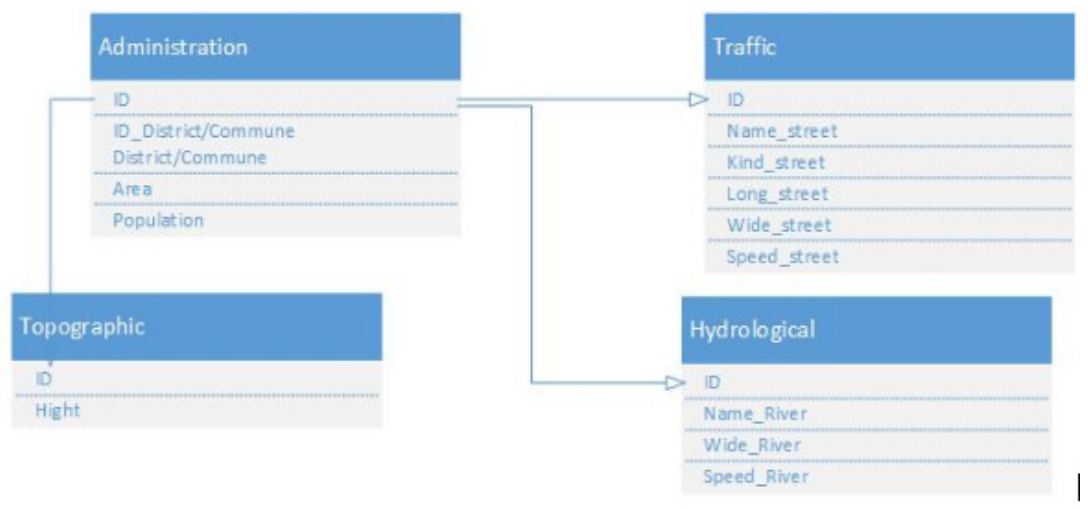

Fig. 4. Information layers for local spatial areas

\subsection{Thematic data classes}

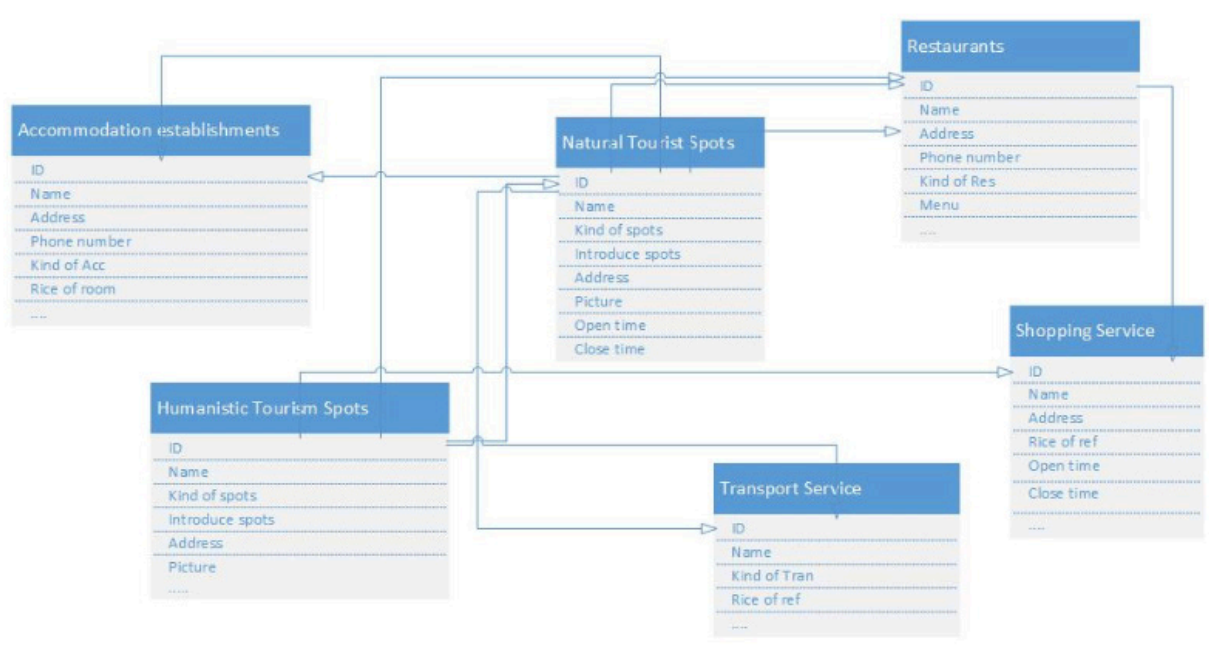

Fig. 5. Data layer Thematic model for smart tourism

Thematic data shows tourist destinations and infrastructure systems, technical facilities, and services for tourism. This is the primary information that meets visitors' specific interests during each trip, so it is essential to elaborate details.

Although the two data models handle spatial data storage differently, both operate in the same relational database environment. 


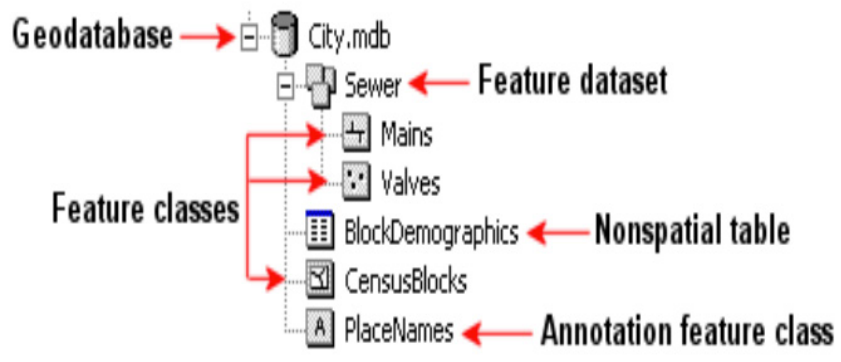

Fig. 6. The geodatabase is a vector data format with ArcGIS $\otimes$ software

\section{Conclusion}

A smart tourism system plays an essential role in using information and communication technology to form an intelligent tourism ecosystem and build a high-quality tourism industry to serve tourists, contributing to sustainable economic development.

An integrated database is an important platform that provides information for destinations in smart tourism development. In line with current tourism development needs, a database should be built in the direction of integrating the most significant information possible. The information contained in it should cover many aspects of the visitors' requirements, including location and spatial relations and object specification features. To have a truly smart tourism environment, certain investments in database development are really necessary for localities that want to develop this trend.

The database is built for smart tourism based on GIS (Geographic Information Systems) is a new direction with the development of IT infrastructure, not outside of building smart cities.

In our future work, Based on the proposed database, continue to research solutions to allocate virtual server resources to meet the processing needs, diverse from smart tourism in the future. Application of artificial intelligence to provide automated services upon the request of smart tourism stakeholders, blockchain applications to manage and develop tourism products, travel cards, etc.

\section{References}

Ames, D. P. (2007). MapWinGIS Reference Manual: A function guide for the free MapWindow GIS ActiveX map component. Lulu. com, Morrisville.

El Mhouti, A., Erradi, M., \& Nasseh, A. (2018). Using cloud computing services in e-learning process: Benefits and challenges. Education and Information Technologies, 23(2), 893-909.

Elsharkawey, M. A., \& Refaat, H. E. (2018). MLRTS: Multi-Level Real-Time Scheduling Algorithm for Load Balancing in Fog Computing Environment. International Journal of Modern Education and Computer Science, 11(2), 1.

Goldberg, A. V., \& Harrelson, C. (2005, January). Computing the shortest path: A 
search meets graph theory. In SODA (Vol. 5, pp. 156-165).

Gong, W., Yan, J., \& Chen, Z. (2014, August). Optimal routing and resource allocation for multimedia cloud computing. In $10^{\text {th }}$ International Conference on Heterogeneous Networking for Quality, Reliability, Security and Robustness (pp. 137-138). IEEE.

Li, Q., Hao, Q., Xiao, L., \& Li, Z. (2009, December). Adaptive management of virtualized resources in cloud computing using feedback control. In 2009 First International Conference on Information Science and Engineering (pp. 99-102). IEEE.

Lo, C. P., \& Yeung, A. K. (2002) Concepts and Techniques of Geographic Information System, Prentice-Hall.

Manca, G., Waters, N. W., \& Sandi, G. (2016). Using cloud computing to develop an integrated virtual system for online GIScience programs. Knowledge Management \& E-Learning: An International Journal, 8(4), 514-527.

Marchionni, B. (2009). Creation of a Geospatial Modeling Environment, Viewer, and Printing Engine (Doctoral dissertation, Idaho State University).

Nan, X., He, Y., \& Guan, L. (2012, September). Optimal allocation of virtual machines for cloud-based multimedia applications. In 2012 IEEE 14 $4^{\text {th }}$ international workshop on multimedia signal processing (MMSP) (pp. 175-180). IEEE.

Nguyen, H. H. C., \& Nguyen, T. T. (2014, November). Algorithmic approach to deadlock detection for resource allocation in heterogeneous platforms. In 2014 International Conference on Smart Computing (pp. 97-103). IEEE.

Nguyen, H. H. C., Solanki, V. K., Van Thang, D., \& Nguyen, T. T. (2017). Resource allocation for heterogeneous cloud computing. Resource, 9(1-2), 1-15.

Rodriguez Sossa, M. A. (2016). Resource provisioning and scheduling algorithms for scientific workflows in cloud computing environments (Doctoral dissertation).

Stillwell, M., Schanzenbach, D., Vivien, F., \& Casanova, H. (2010). Resource allocation algorithms for virtualized service hosting platforms. Journal of Parallel and distributed Computing, 70(9), 962-974.

Walsh, W. E., Tesauro, G., Kephart, J. O., \& Das, R. (2004, May). Utility functions in autonomic systems. In International Conference on Autonomic Computing, 2004. Proceedings. (pp. 70-77). IEEE.

Xiao, Z., Song, W., \& Chen, Q. (2012). Dynamic resource allocation using virtual machines for cloud computing environment. IEEE transactions on parallel and distributed systems, 24(6), 1107-1117.

Yazir, Y. O., Matthews, C., Farahbod, R., Neville, S., Guitouni, A., Ganti, S., \& Coady, Y. (2010, July). Dynamic resource allocation in computing clouds using distributed multiple criteria decision analysis. In 2010 IEEE 3rd International Conference on Cloud Computing (pp. 91-98). leee.

Zhan, F. B. (1997). Three fastest shortest path algorithms on real road networks: Data structures and procedures. Journal of geographic information and decision analysis, 1(1), 69-82.

Submitted 16.03.2020 Accepted 21.05.2020 